\title{
El culto al bronceado
}

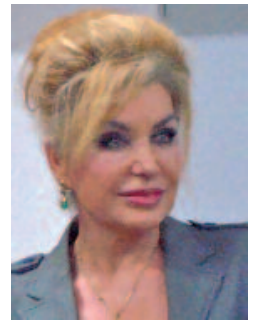

Aurora Guerra-Tapia

Profesora titular de Dermatología. Departamento de Medicina.

Facultad de Medicina.

Universidad Complutense de Madrid.

Jefa de sección de Dermatología.

Hospital Universitario

12 de Octubre. Madrid.

Profesora de Dermatología.

Universidad Internacional

de La Rioja (UNIR).

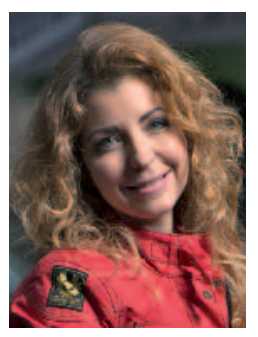

\section{Elena González-Guerra}

Profesora asociada de Dermatología.

Departamento de Medicina.

Facultad de Medicina.

Universidad Complutense

de Madrid.

Médico adjunto.

Servicio de Dermatología.

Hospital Clínico San Carlos. Madrid.

Profesora de Dermatología.

Universidad Internacional

de La Rioja (UNIR).
El interés acerca del conocimiento del color de la piel se ha incrementado en las últimas décadas coincidiendo con una mayor sensibilidad social hacia la salud y el estilo de vida activo como símbolo de juventud. Aunque la antropología y la biología dieron los primeros pasos, la dermatología ha tomado el relevo acertadamente.

El principal elemento que «da color» a la piel es la melanina: eumelanina, que caracteriza a las pieles oscuras, y feomelanina, propia de las pieles claras. Pero no solo es el tipo de pigmento lo que determina la intensidad de coloración. También lo hacen el número y tamaño de los melanosomas —orgánulos precursores- existentes en melanocitos y queratinocitos, y su grado de melanización, dispersión, transporte y degradación. El color de la piel determinado genéticamente sin influencia de la radiación solar se denomina pigmentación constitutiva, mientras que el modificado por la radiación solar se llama pigmentación facultativa o bronceado.

La descripción inicial del color constitutivo de la piel —blanco, negro, marrón, amarillo, rojo- fue sustituida por métodos más objetivos y reproducibles como la escala cromática de Von Luschan (1897), basada en un muestrario de 36 tonalidades con las que comparar la piel de una zona cutánea habitualmente no insolada. La escala de Fitzpatrick o los fototipos cutáneos, con seis definiciones de color basadas en la respuesta a la radiación ultravioleta, sigue en uso desde 1975. La espectrometría de reflectancia —que mide la absorción de una radiación electromagnética al atravesar la piel- y sus variantes es desde la década de 1950 un exacto método para conocer los matices cutáneos.

La blancura de la piel ha sido símbolo de feminidad y belleza durante la mayor parte de la historia de la humanidad, y aún lo es en determinadas culturas. Los referentes artísticos lo atestiguan ${ }^{1}$. Del mismo modo, ha sido atributo de una vida alejada de los 
trabajos a la intemperie y, por lo tanto, de clase elevada, como lo revelan las modas en el atuendo - cuellos altos, guantes, sombreros-y la profusión de cosméticos simuladores de blancura.

Sin embargo, el gusto por la piel morena es reciente. Fue Coco Chanel quien dictó la moda del bronceado cuando, en 1929, enunció que «un color tostado de la piel es el índice de lo chic, de lo que debe llevarse».

El impulso de la publicidad de las revistas femeninas — sobre todo, entre 1920 y 1930 - fue un colaborador necesario en esta creación. Un sugestivo trabajo que revisa la influencia de Vogue y Harper's Bazaar de los años 1920, 1927, 1928 y 1929 descubre un significativo número de artículos promotores del bronceado ${ }^{2}$. Incluso alguna revista francesa celebraba la economía de unas piernas bronceadas sustitutivas de las inasequibles medias de seda, y enseñaba el método para pintar a lo largo de la cara posterior de la pierna una raya recta que imitara la costura original de estas.

Es posible también que este cambio sorprendente en las actitudes sociales fuese favorecido por los descubrimientos médicos que avalaban los beneficios de la helioterapia en el tratamiento de la tuberculosis y el raquitismo. Ya en 1903, Niels Ryberg Finsen había sido premiado con el Nobel por el tratamiento con sol de una forma de tuberculosis cutánea, el lupus vulgar.

En el siglo XXI, pese a la información médica difundiendo la certeza de los efectos deletéreos del sol sobre la piel, el bronceado mantiene sus valores estéticos en la población. Un estudio realizado por Knight et al. ${ }^{3}$ en 2002 determinó que más del $90 \%$ de los usuarios de camas de bronceado insistían en su práctica por razones estéticas, pese a conocer los riesgos del envejecimiento prematuro y el cáncer de piel.
En un curioso trabajo ${ }^{4}$ de 2015 , se evaluaron 69 ejemplares de revistas de temas deportivos de Estados Unidos, analizando 4683 imágenes. Tanto las mujeres como los hombres aparecían con una piel bronceada, pero los hombres tenían una tonalidad un $54 \%$ más oscura que las mujeres.

En la misma línea, el trabajo de McWhirter y Hoffman-Goetz ${ }^{5}$ examinó el contenido de seis revistas canadienses femeninas (Chatelaine, Canadian Living, Homemakers, Flare, Fashion y Elle Canadá) entre 2000 y 2012. Aunque había numerosas páginas sobre fotoprotección y bronceado, solo el $15 \%$ de los artículos y el $1 \%$ de las imágenes desanimaban al bronceado, mientras que el $41 \%$ de los artículos y el $53 \%$ de las imágenes alentaban a este.

La ciencia médica, la dermatología, no puede ceder en su obligación de educar sanitariamente. El bronceado es un camino hacia el envejecimiento y el cáncer de piel. Y eso no tiene objeciones ni excepciones. Nuestra misión es informar. El libre albedrío de cada uno dirá la última palabra.

\section{BIBLIOGRAFÍA}

1. Guerra Tapia A. Mirando al sol o cuando la fotoprotección no existía. Más Dermatol. 2013;21:31-3.

2. Martin JM, Ghaferi JM, Cummins DL, Mamelak AJ, Schmults $\mathrm{CD}$, Parikh $\mathrm{M}$, et al. Changes in skin tanning attitudes. Fashion articles and advertisements in the early 20th century. Am J Public Health. 2009;99(12):2140-6.

3. Knight JM, Kirincich AN, Farmer ER, Hood AF. Awareness of the risks of tanning lamps does not influence behavior among college students. Arch Dermatol. 2002;138(10):1311-5.

4. Basch CH, Hillyer GC, Ethan D, Berdnik A, Basch CE. Tanning shade gradations of models in mainstream fitness and muscle enthusiast magazines: implications for skin cancer prevention in men. Am J Mens Health. 2015;9(4):301-6.

5. McWhirter JE, Hoffman-Goetz L. Skin deep: Coverage of skin cancer and recreational tanning in Canadian women's magazines (2000-2012). Can J Public Health. 2015;106(4):e23643. 